\title{
A TEST CASE FROM NORWEGIAN RURAL AREAS WHERE STRUCTURED USER PARTICIPATION BUILDS SAFER COMMUNITIES
}

\author{
Anna Maria Urbaniak-Brekke ${ }^{1}$, Ivar Petter Grøtte and Øyvind Heimset Larsen \\ ${ }^{1} \mathrm{PhD}$ \\ Western Norway Research Institute \\ Royrgata 4, 6856, Sogndal, Norway
}

\begin{abstract}
Paneda in Selje, Norway is among the foremost DAB technology companies in the world and works with warning systems for citizen evacuation. Their alert technology will be part of the national warning system, but first research, testing, evaluation and adjustment must take place. The case here is about the first test of the method, which has been used in large ICT projects. In this first stage of the project pupils from a local school in Selje at the west coast of Norway are involved in the development and implementation, with advice and direction of Western Norway Research Institute and Paneda. The results also suggest that the structured and staged testing framework may also provide a framework for local mobilisation, learning and implementation for new digital services.
\end{abstract}

\section{KEYWORDS}

User Experience, Experience Design, Evaluation, Public Warning Systems

\section{INTRODUCTION}

Warning of citizens and society in emergency situations has become increasingly important, due to many factors occurring in everyday life. Danger of terror attacks in large urban centres, effects of climate changes, such as floods, avalanches, fires, and many more threats, make societies in Norway, as well as all over the world, very vulnerable (Gentry \& Gordon, 2019; Rød et al, 2019). It is therefore essential to develop resilient and robust systems to be able to avoid consequences of unexpected events setting human life in danger. Those systems are needed both in order to try to predict and avoid the events, but also to minimize potential losses if the emergency already occurs. Public warning technologies are being developed in order to inform citizens who can be in danger and guide them to a safer place when an unexpected and dangerous event takes place (Bean, 2019; Toyoda \& Kanegae, 2014). Paneda, a company situated in Selje, in Western Norway is a pioneer in creating new public warning technology. Together with partner-companies, they prepared a highly innovative system for informing people about a dangerous situation (like a terror attack or natural disaster) and helping them to get to a safe place. However, this new technology that is being developed needs structured and iterated testing and evaluation before it will be introduced to a broader market. Structured technical testing and user testing is a necessary procedure before any system or innovation can be accepted and used publicly. Real-life tests cannot be replaced by other types of studies, marked research or data modelling (Drucker, 2007). Pilots and prototype-testing should be conducted for all new technologies despite the field, but are common especially for ICT, energy and health (Eide \& Ljunggren, 2018). Testing is important for the development and learning of the company behind the technology. Eide and Ljunggren explain that a test can be conducted with both internal and external participants, and in many different forms: a prototype or pilot testing, reconnaissance or exercises, observations and feedback, as well as evaluation interviews and questionnaires (2018). Testing a technology before introducing it to the public should be especially important when it comes to developments that can have a crucial influence on human health and life. 
This paper's main goal is to present a testing method and its use as a framework for both testing and introducing a public warning technology. The test of the method, which has previously been useful in large ICT projects, is organized as a case where 9th grade students from Selje are involved in local installation and evaluation of the technology, with the advice and direction of Western Norway Research Institute (WNRI) and the Paneda company. The test group involves students from 1st to 10th grade. The test case is the following: A major gas leakage in the nearby area. How to manage the risk of disasters, public warning and citizen evacuation in small communities near large transport systems? What are the good methods for user mobilization and involvement in service development? Will the new technology we introduce work and which parts of it need improvement? And finally will the testing framework in itself work as an efficient method for introducing the technology for the local population? As the test was conducted in June 2021, and not all results are deeply analysed, this is a work in progress.

\section{BODY OF PAPER}

Below we first present the theory, then briefly introduce the Public Warning System project, and describe the Selje-test that is a part of it, together with the method used, and preliminary results. The application of this testing method is innovative in itself, mobilising and involving the local society, and what is more young school pupils, in conducting the test both as the ones being evacuated and the ones responsible for leading the evacuation and evaluation of it.

\subsection{Theory}

In this research project, with the technology companies, we use an action research approach. We are participants in the development, and we expect to ground our conclusions in this action research (Greenwood and Levin 2007). Case study research is a key element as "the study of the particularity and complexity of a single case, coming to understand its activity within important circumstances" (Stake 1995). Our study is a single case where we look into a specific local community. According to Yin (1981) the strength of the case study is that it both covers a contemporary phenomenon and its context. Our findings will be from a single case, but we claim that these findings also can be a "force of example" (Flyvbjerg 2006) for other communities facing similar challenges related to emergencies and population evacuation. Greenwood and Levin (2007) define action research as collaborative social research carried out by a team of action researchers and members of local organizations who are trying to improve the local situations. Together, the researcher and the actors "define the problem to be examined, cogenerate relevant knowledge about them, learn and execute social research techniques, take actions, and interpret the results of actions based on what they have learned" (Greenwood and Levin 2007).

\subsection{PWS Project}

"Public Warning System" (PWS) is a national-range project which aims to research, develop and test a new and complete future population warning and evacuation system built on the DAB network (digital radio broadcasting network) (Vestlandsforsking, 2020). The project is co-financed by the Norwegian Research Council. The system shall alert and evacuate the population at critical incidents in a defined area and regardless of language and nationality. The warning will be given via audio, image, text, video, sirens, roadblocks/barriers, start/stop of machines etc, as shown in Figure 1. The need has been clearly demonstrated through many acts of terrorism, extreme weather and environmental disasters. Authorities lack good enough alert systems, while the EU sets requirements for population warning. Norway has the same requirements through the EEA Agreement (European Union, 2018).

The need for an innovative solution is clear, as existing systems have several problems. The mobile network is often out of service when it is needed the most and many people do not listen to the radio, have their mobile phone with them or do not use mobile phones at all. In addition, there is a significant problem with distance/time-factor before the emergency services arrive, and how to evacuate large crowds immediately. 
During the project's lifetime (from 2020 to 2023) research work related to multiplatform and management systems will be carried out, technical testing (verification) and user testing (validation) activities will be prepared and implemented for a set of pilot services, and finally various dissemination activities will be carried out. A good networking practice for knowledge-based development should identify the correct balance between business, research and government. (Larsen et. al 2018) The publicly funded network initiatives and innovation projects like this one, in Norway, typically encourage the triple helix actors (Etzkowitz and Leydesdorff 2000) within a region to collaborate and thus bridge the gaps between the actors.

This paper describes a structured and staged test of the technology, performed in June 2021 at Selje school in Western Norway, together with thoughts around the topic from both a representative of the company developing this DAB solution and authorities responsible for disaster management in the region.

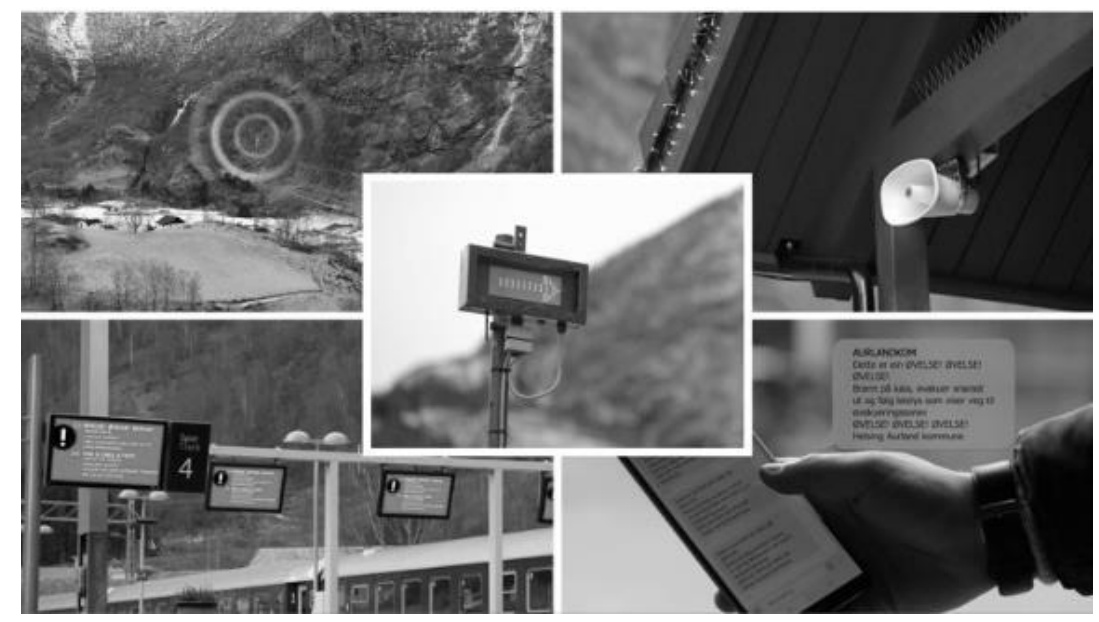

Figure 1. The elements of the Public Warning System (Vestlandsforsking, 2020)

\subsection{Description of the Test}

The test described in this paper was supposed to be carried out in March 2021, but due to a Covid-19 outbreak in the region, it was postponed to the middle of June 2021. The primary goal of the test is to check the operation of the proposed hazard warning system based on the DAB technology for a local school. This exercise was conducted in close cooperation with the Selje school, which gathers pupils from the 1st to 10th grade in Norwegian school system. An inspiration for this special test came with a request from the school regarding the 9th grade having a 'hands-on' experience with working with technology. Since Paneda, this rapidly growing, innovative company has its headquarters just a few hundred meters from the school, they were contacted and responded positively. The idea was then to test the warning system in the school premises, using DAB signal to turn on specific equipment giving light, sound, texts and picture effects in order to warn about an emergency and support an evacuation action. Since Vestlandsforsking leads the evaluation work package of the PWS project mentioned above, our task is also to develop testing scenarios and evaluation schemes for conducting the tests. In the Selje-test we decided to use a modern method to involve the end users and society, in this case the pupils and teachers, in performing the test and evaluating it. The scenario idea, a major gas leak close to the school, was accepted and the equipment for the test, such as screens, lights and speakers, were prepared, as well as the evaluation tools were defined. The public warning system with the equipment and technology mentioned above was installed, technical testing (verification) was performed also involving the 9th grade project group of pupils, acceptance of the total integrated system was signed out and the user test (validation) was ready to start. Then an evaluation scheme was distributed by the 9th grade pupils among the other pupils, and the user test was ready to start. An alarm went off, informing pupils and teachers being outside the school premises about a hazardous emergency and a need to seek a specific safe place inside the school. Pupils and teachers responded to the alarms and warnings and reached their planned destinations. After finishing the test the pupils of each class had to fill out the user test forms and each class had a de-briefing. Furthermore, the teachers were also interviewed about their experiences of this test-evacuation by the researchers. 


\subsection{Preliminary Results}

The reflections of the representative for the company developing this unique DAB technology concentrates around the fact that the current public warning system in Norway is based on SMS, which means dependence on the mobile phone coverage and people's relation to using it. This is why they suggest including DAB-network and taking over of electronic equipment as a supplement for the current technology. However, the company notices that reaching public authorities in Norway with this idea has been difficult, and because of that a cooperation with a school in order to test the system was very welcomed. Another reason for it is that schools play an important role in each society, and through them, information about the det system and evacuation exercise can be spread. Also, close cooperation with other companies, police, fire department and local and regional disaster management authorities is sought. Nevertheless, there is an acknowledgement of a clear need for more tests in the future, before the technology is introduced on a national level. New tests are already being planned in other Norwegian regions where natural disasters are threatening the communities.

An interview with the disaster and emergency manager of the Vestland region confirmed the need for the new services. No modern integrated citizen alert and evacuation system exists and the need for improved services are very much needed. The role of local schools as a local HUBs for mobilisation, learning and implementation of this type of general citizen services are seen as an interesting case for further study and research.

Our preliminary results are gathered from the questionnaires evaluating the warning and evacuation of Selje school that were filled out by the students at the school in Selje (1st to 10th grade) and invited guests (teachers, authorities, journalists), a discussion after the test, and participating observations of the researchers. It turns out to be very important that the warning system and its elements are adjusted to the needs of different arenas where members of the society are present: schools, welfare units, industry, public places. At the same time it has to cover several scenarios: flood, gas leakage, avalanche, tsunami. The system must also be tested often and kept updated, so that when the need comes, it works immediately. The students of the 9th grade (usually 15 years old) seem to be a group that can easily get engaged in an exercise like this, from development of scenarios, test of the technical equipment, to the evaluation. However, it turns out that they are most interested in the technical and 'hands-on' tasks, and less in the theoretical part of it. This gives us a hint on how to develop such exercises in the future so that they can successfully involve the younger representatives of the society. From the technical point of view, we can confirm that sound plays a bigger role in warming than pictures and text, as it was the information coming from loudspeakers that was most important for both the students and adult guests. Nevertheless, the text and pictures on the screens must be customized, so that they are understandable for most people despite age, level of education or country of origin, such as internationally used pictograms and information in several languages (e.g. in Selje-test the text on the screens and from the loudspeakers was in three languages: Norwegian, English and Arabic, due to the fact that students in this school are using those languages).

\section{CONCLUSION}

The PWS project represents research in progress where the first field trials were run in June 2021. We gathered the first feedback on the effects of the structured testing methodology used as the key framework both for verification and validation testing in itself, but also as a method for local community mobilization and involvement in the citizen evacuation procedures. The test was successful, showing the possibilities of improvement and adjustments. Students turn out to be a group that can easily get engaged in such exercises and learn through them. Interestingly, different societal groups (students in different ages, teachers, researchers, technology developers and other guests) shared similar experiences, which shows that such a system can be developed to serve all. Finally, this test showed the potential of DAB-technology for public warning, and the way in which it should be further developed and tested.

The new prototype services will continue to be evaluated against the user requirements defined during the early stages of the project. In particular, the objective of evaluation will be to optimize the interaction between end-user feedback and technical implementation. And in addition this structured and staged testing framework might also prove to be an efficient framework for the introduction and the mobilisation for new digital services in a local community. The local schools might become the local HUBs for introducing new general digital services where the schools provide the needed infrastructure as well as learning facilities and related human resources. 


\section{ACKNOWLEDGEMENT}

The authors have no conflict of interests.

\section{REFERENCES}

Bean, H. 2019. Mobile Technology and the Transformation of Public Alert and Warning. ABC-CLIO, LLC, Santa Barbara, Denver.

Drucker, P. F. 2007. Management Challenges for the 21st Century. Elsevier Ltd, Oxford.

Eide, D. et al, 2018. Testing som metode i innovasjonsprosesser - Et verktфyhefte med eksempler fra opplevelsesbasert reiseliv. Sourced from: https://docplayer.me/100186619-Testing-som-metode-i-innovasjonsprosesser-etverktoyhefte-med-eksempler-fra-opplevelsesbasert-reiseliv-av-dorthe-eide-og-elisabet-ljunggren.html.

Etzkowitz H, Leydesdorff L. 2000. The dynamics of innovation: from national systems and "mode 2" to a triple helix of university-industry-government relations. Res Policy, 29(2):109-123.

European Union. 2018. Directive (EU) 2018/1972 of 11 December 2018 establishing the European Electronic Communications Code. Official Journal of the European Union. Sourced from: https://eurlex.europa.eu/eli/dir/2018/1972/oj.

Flyvbjerg, B. 2006. Five Misunderstandings About Case-Study Research. Qualitative Inquiry, 12(2), 219-145.

Gentry, J.A. et al, 2019. Strategic Warning Intelligence: History, Challenges, and Prospects. Georgetown University Press. Washington DC.

Greenwood, D. J. et al, 2007. Introduction to Action Research 2nd edition. Social Research for Social Change. Sage Publications, Thousand Oaks, CA.

Larsen, Ø.H. et al, 2018. The Public Sector's Role in Norwegian Network Cooperation: Triple Helix or Laissezfaire? Triple Helix, Springer Open, DOI: 10.1186/s40604-018-0052-x.

Rød, J.K. et al, 2019. Er norske kommuner klare for en farligere fremtid? Plan, 4(51) 6-11. DOI: 10.18261/ISSN15043045-2019-04-03.

Stake, R.E. 1995. The Art Of Case Study Research. Sage Publications, Thousand Oaks, CA.

Toyoda, Y. et al, 2014. A community evacuation planning model against urban earthquakes. Regional Science. Policy \& Practice, 6(3), 231-249. DOI: 10.1111/rsp3.12036.

Vestlandsforsking. 2020. Public Warning System (PWS). Sourced from: https://www.vestforsk.no/en/project/publicwarning-system-pws.

Yin, R. K. 1981. The case study as a serious research strategy. Knowledge, 3, 97-114. 